\title{
SEARCH FOR PROPANIL RESIDUES IN RICE BY UV-VISIBILE SPECTROPHOTOMETRY AND FTIR AT THE NATIONAL HEALTH LABORATORY IN BAMAKO, MALI
}

\author{
Tidiane DIALLO ${ }^{1,2 *}$, Brahima B. TRAORE ${ }^{3}$, Abdourahamane DIARA ${ }^{1}$, Haoussa COULIBALY ${ }^{2,3}$ and Benoit \\ Yaranga KOUMARE ${ }^{1,2}$ \\ ${ }^{1}$ Faculty of Pharmacy of Bamako, University of Sciences, Techniques and Technologies of Bamako, Mali \\ ${ }^{2}$ National Health Laboratory, Mali \\ ${ }^{3}$ Institute of Applied Sciences / University of Sciences, Techniques and Technologies of Bamako, Mali
}

https://doi.org/10.35410/IJAEB.2022.5704

\begin{abstract}
Context: farmers, to increase productivity, increasingly resort to fertilizers and pesticides. Propanil is one of the pesticides used to improve the yield of rice, but the presence of its residue in quantity is said to be toxic to humans and animals.

Objective: implementation of a technique to search for Propanil residues in rice by the UVvisible spectrophotometry method and Fourier transform infrared spectroscopy (FTIR).

Materials and Methods: this was an experimental study, carried out within the food and drink quality control service of the National Health Laboratory. The UV-visible spectrophotometry method allowed us to quantify the Propanil content in rice. The FTIR was used for identification through the spectral overlay.
\end{abstract}

Results: our study allowed us to:

- Dose the rice in accordance with the maximum residue limit $(0.01 \mathrm{ppm})$ by UV-visible spectrophotometer with a result of $107.1 \%$;

- To identify the presence of Propanil in the rice by superimposing the images of the standard and the sample at the same concentration of $0.01 \mathrm{ppm}$.

Conclusion and outlook: other additional studies must be carried out in order to validate this method and extend it to other varieties of rice in order to guarantee the safety of the rice consumed in Mali.

Keywords: Rice, Propanil, UV-visible spectrophotometry, FTIR.

\section{INTRODUCTION}

The term pesticide is used to designate all natural or synthetic substances which can control, repel, kill or stop the development of living organisms (microbes, animals or plants) considered to be harmful to the development of agricultural productions, to hygiene or to the public health (cockroaches in homes and parasitic insects such as lice, mosquitoes, etc.) [1].

Pesticides improve the yield and quality of products by protecting crops against pests. 
Propanil (3,4-dichloropropionanilide) is a pesticide of the herbicide family used in irrigated rice cultivation. It is a selective, short-lasting post-emergence contact herbicide [2]. It is authorized by the Sahelian Pesticide Committee to control annual weeds in rice cultivation.

Rice is the staple food of more than half of the world's population [3]. According to the latest surveys carried out in 2018/2019 by the National Institute of Statistics of Mali, the annual consumption of rice amounts to approximately 3.14 million tons, an increase of $7.5 \%$ compared to the result of the last season (2.92 million tons) [4]. Rice thus becomes the first cereal consumed in urban areas. In Bamako, more than half of consumption is provided by imports. It was noted that in general, rural populations are increasingly eating imported rice [3]. However, despite the increasing increase in its production, Mali is forced to resort to imports to meet its needs. Thus, $45 \%$ of rice sold on the national market comes from imports [3].

According to a report by the Food and Agriculture Organization of the United Nations (FAO), the world population will reach 9 billion people by 2050. To meet the food needs of this growing population, agricultural production must increase by $70 \%$, or even doubled, in developing countries [5]. It is therefore necessary to increase agricultural yields and regularize production. Protecting crops against pests and diseases is therefore essential. In this context, the use of products that can fight against these "enemies" of crops is a powerful lever. Faced with this situation, the technical health structures must strengthen the health security of imported and / or locally produced rice through quality control in the laboratory.

Thus, we initiated the present study with the aim of monitoring the quality of locally produced rice in relation to Propanil contamination. The objective of this study was to search for Propanil residues in Gambiaka rice sold at the "Niono place" market in Bamako by UV-Visibile and Infrared Fourier Transformer (FTIR) spectrophotometry at the National Health Laboratory.

\section{MATERIALS AND METHODS}

The study was carried out at the food and drink quality control department of the National Health Laboratory (LNS) of Bamako-Mali, between August and October 2020.

This was a qualitative and quantitative analytical study based on the search for residues of Propanil in rice by UV - Visible Spectrophotometry and FTIR at LNS.

We randomly sampled three types of rice according to the size of the seed (small, medium and large). So we got a total of three samples.

Our samples were analyzed in accordance with the QUECHERS method according to ISO standard NF / EN 15662 [6].

From the maximum residue limit (MRL) of Propanil in rice $(0.01 \mathrm{ppm})$, we prepared a solution 10 times the MRL or $0.1 \mathrm{ppm}$ and $1 / 10$ th of the MRL or $0.001 \mathrm{ppm}$ in addition to the MRL 0.01 ppm ie a range of three solutions $0.1 \mathrm{ppm}, 0.01 \mathrm{ppm}$ and $0.001 \mathrm{ppm} \mathrm{[7].} \mathrm{These} \mathrm{different}$ concentrations will allow us to determine the optical density of the standard. From the reading of the samples with UV-visible spectrophotometry, we will have their optical densities [8]. We will 
thus have to determine the Propanil content of these samples from the ratio of the optical density of the sample and that of the standard, multiplied by 100 .

$$
\mathrm{T}(\text { Propanil content of sample })=\frac{\text { optical density of the sample }}{\text { optical density of the standard }} * 100
$$

Standards 90.0-110.0\%

For reasons of confidentiality, the identities of the sellers will be kept secret, the samples will be coded with numbers.

The UV-Visible Spectrophotometry software (AGILENT Cary Win UV) was used to directly process the data for the calculation of absorbances and concentrations for each analysis.

The FTIR, allowed us to carry out the identification of Propanil through the spectral superposition between the blank, the sample, and the standard [9].

\section{RESULTS}

a. Result FTIR: Identification of Propanil

Figures 1 to 3 allowed us to obtain the graphic interpretation of the different assumptions.

The Standard chromatogram and the sample are the same but the blank is different. These findings allow us to confirm that the quantity of Propanil present in the rice samples that we analyzed is equal to $0.01 \mathrm{ppm}$ of the concentration of the standard.

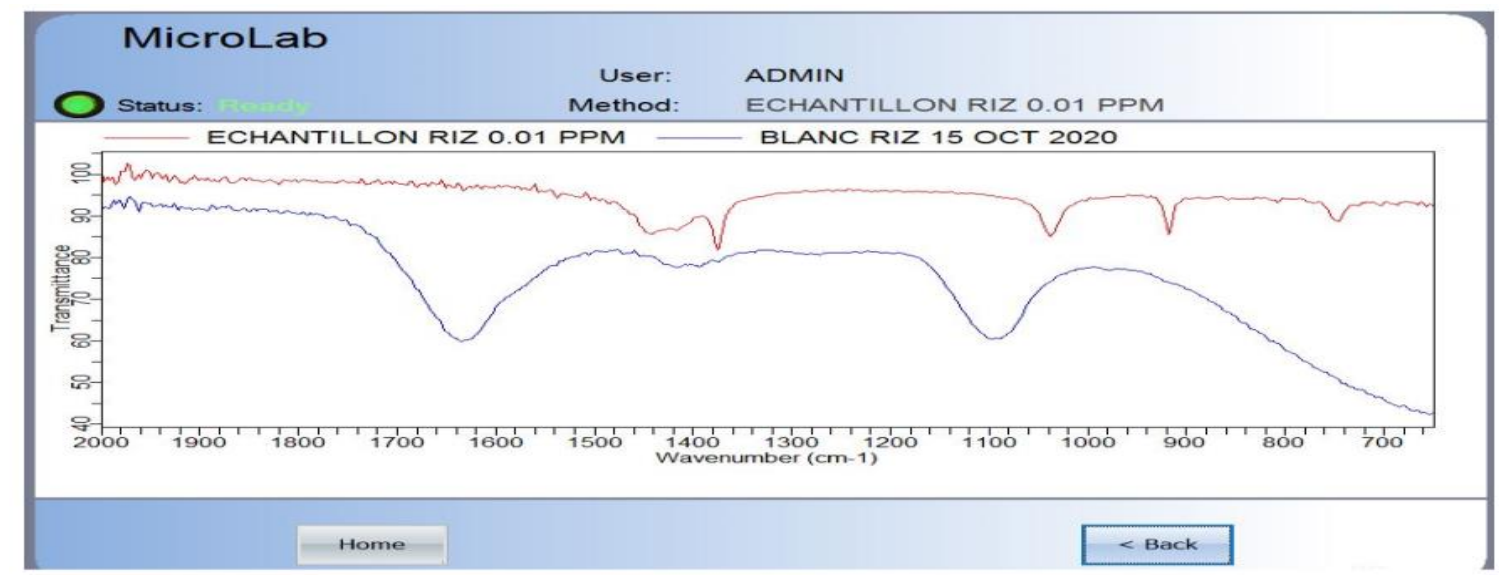

Figure 1: Infrared spectra of white and sample 
International Journal of Agriculture, Environment and Bioresearch

Vol. 07, No. 01; 2022

ISSN: $2456-8643$

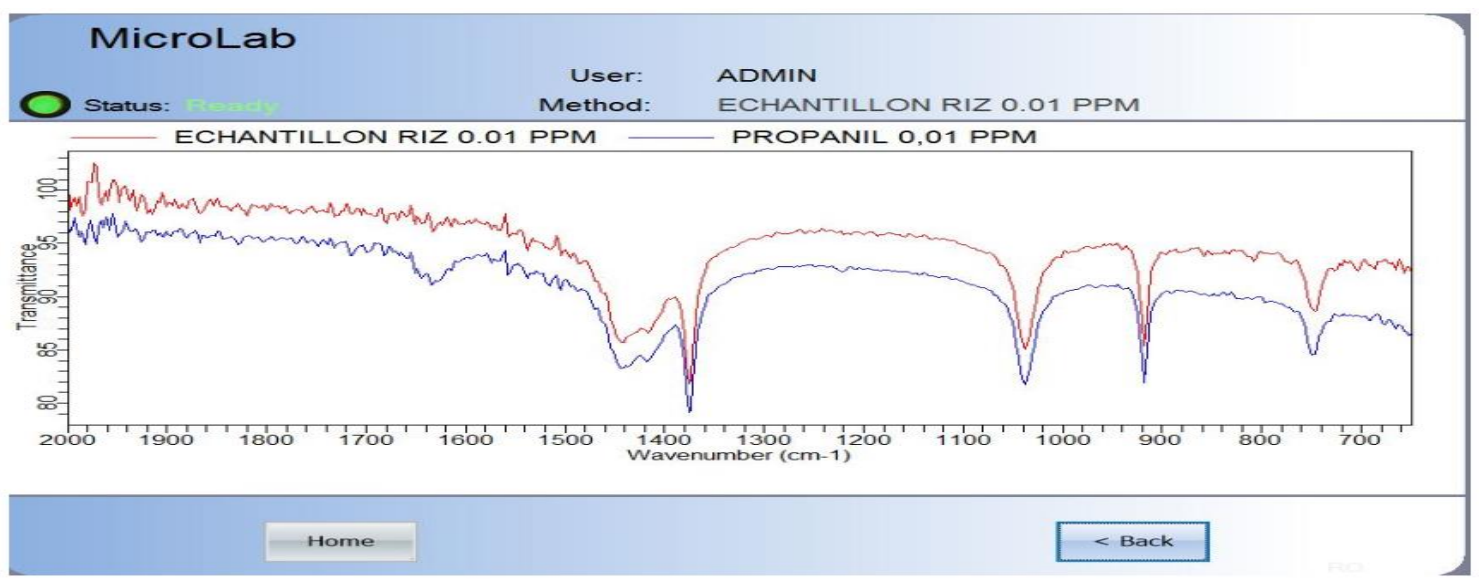

Figure 2: The infrared spectra of the standard and the sample were guessable

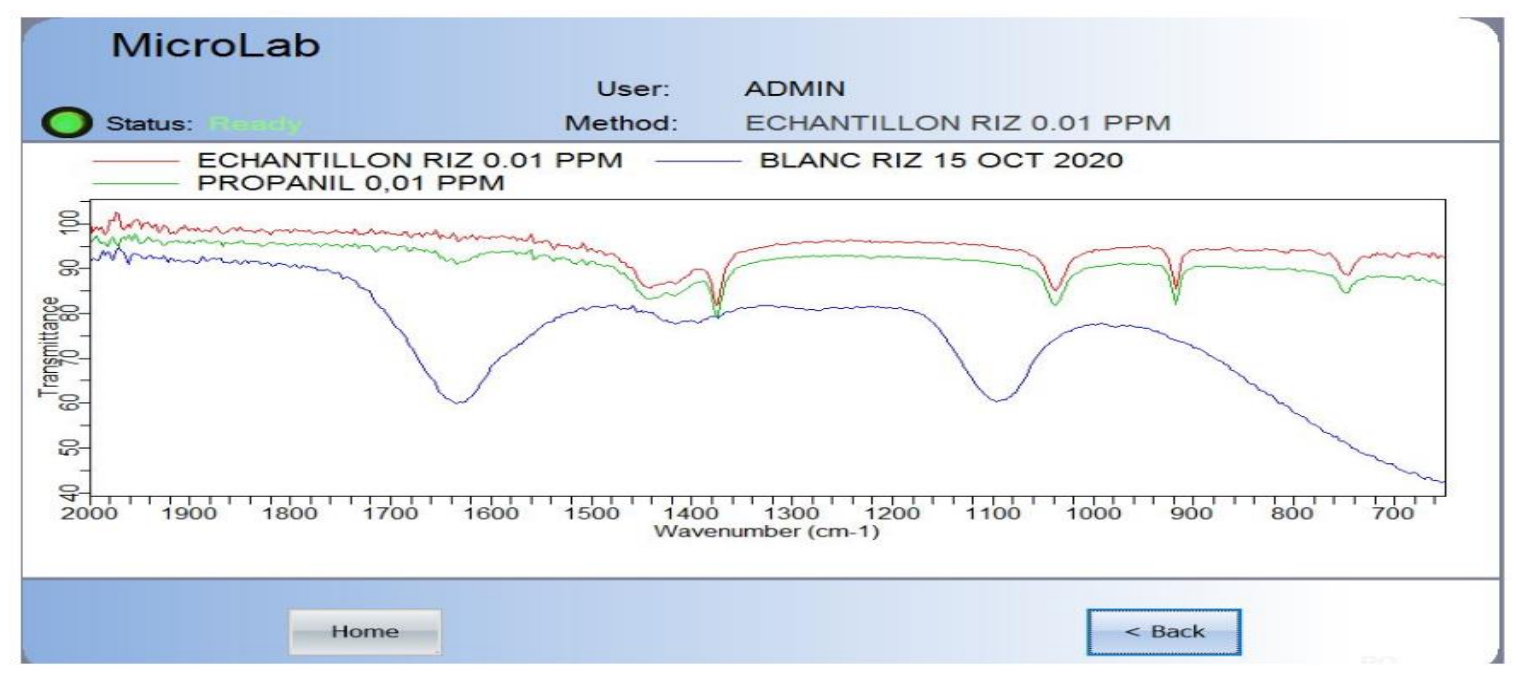

Figure 3: The infrared spectrum of white clearly distinct from those of the standard and the sample at the same concentration.

The spectral profile of the sample is different from that of white. 
b. UV-visible spectrophotometry result: Propanil determination Tables I to III, allowed us to obtain the Propanil content of our sample.

The standard was identified at a well determined wavelength $270-280 \mathrm{~nm}$ for three different concentration ranges $0.1 \mathrm{ppm} ; 0.01 \mathrm{ppm}, 0.001 \mathrm{ppm}$. The optical density of the standard at 0.01 ppm was 0.928 (table I).

Table I: UV Spectrophotometry - Standard Visible

\begin{tabular}{|l|l|l|l|}
\hline $\mathbf{N}^{\circ}$ & Wavelengths & Concentrations & Optical densities \\
\hline 1 & 275 & 0,001 & 0,141 \\
\hline $\mathbf{2}$ & $\mathbf{2 7 0}$ & $\mathbf{0 , 0 1}$ & $\mathbf{0 , 9 2 8}$ \\
\hline 3 & 270 & 0,1 & 3,987 \\
\hline 4 & 280 & 0,1 & 4,367 \\
\hline
\end{tabular}

The Absorbance (optical density) of the sample at $0.01 \mathrm{ppm}$ was 0.994 (table II).

Table II: Results of absorbance of the sample by UV spectrophotometry - Visible

\begin{tabular}{|l|l|l|l|}
\hline $\mathbf{N}^{\circ}$ & Wavelengths & Sample Concentration & Optical densities \\
\hline 1 & 270 & 0,1 & 0,797 \\
\hline $\mathbf{2}$ & $\mathbf{2 7 0}$ & $\mathbf{0 , 0 1}$ & $\mathbf{0 , 9 9 4}$ \\
\hline 3 & 275 & 0,1 & 0,808 \\
\hline 4 & 280 & 0,1 & 1,206 \\
\hline
\end{tabular}

We obtained a content of $107.1 \%$ which complies with the standard (90\% -110\%) see table III.

Table III: Determination of the Propanil content

\begin{tabular}{|l|l|l|l|l|}
\hline Setting & Wavelengths & Concentration & Optical densities & \% content \\
\hline Standard & \multirow{2}{*}{270} & 0,01 & 0,928 & $107,1 \%$ \\
\cline { 1 - 2 } Sample & & 0,994 & \\
\hline
\end{tabular}


The figure 4 gives us; the peaks of the Standard and the sample came out at the same wavelength (or 270nm) and at the same concentration $(0.01 \mathrm{ppm})$.
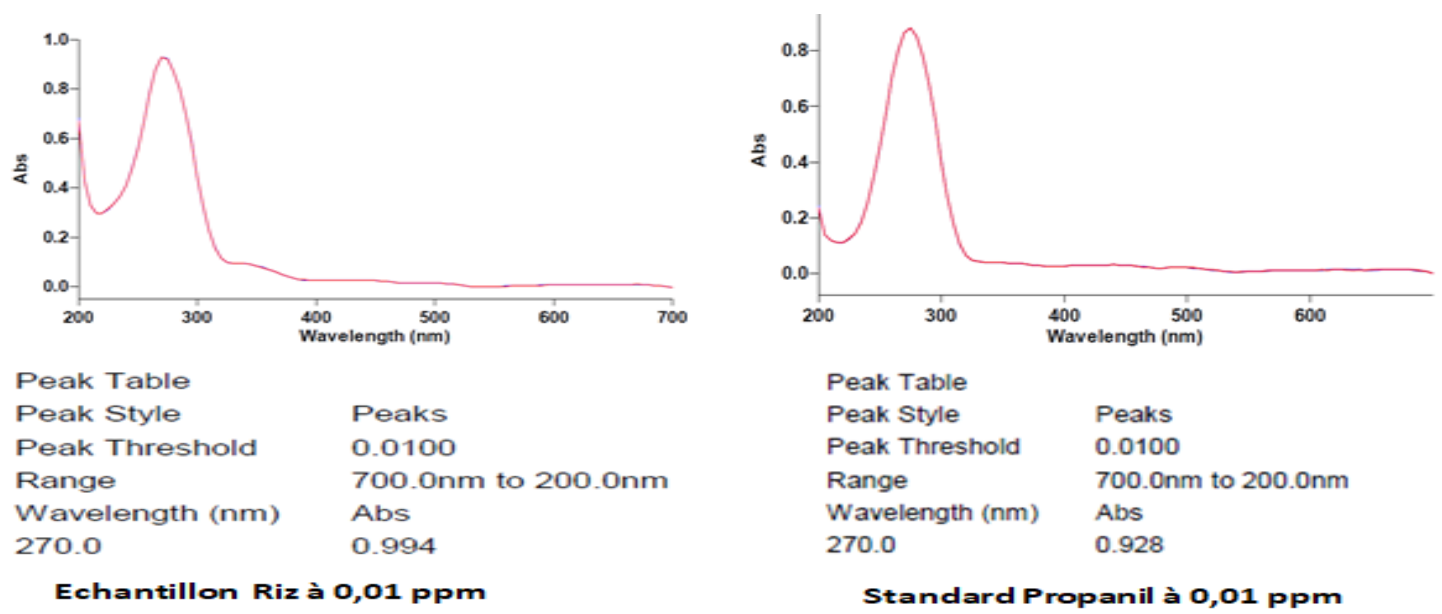

Figure 4: Comparison of Standard and Sample Peaks

\section{DISCUSSIONS}

- The spectrum of the sample was different from the blank (Figure 1)

- The spectrum of the standard and the sample were identified at wavelengths $1360 \mathrm{~nm}, 1020$ $\mathrm{nm}, 900 \mathrm{~nm}$ and $740 \mathrm{~nm}$ for a concentration of standard $0.01 \mathrm{ppm}$ and the sample $0.01 \mathrm{ppm}$ (Figure 2). .

- The spectrum of the Standard and the sample were identical but that of the white is different (Figure 3).

These findings allowed us to confirm that the quantity of Propanil present in the rice samples that we analyzed is equal to $0.01 \mathrm{ppm}$ of the concentration of the standard.

We noticed that at the wavelength of $275 \mathrm{~nm}$ with a concentration of $0.001 \mathrm{ppm}$ the optical density is 0.141 . This optical density was low compared to the required standard (0.4 - 0.9).

- At $270 \mathrm{~nm}$ wavelength and with a concentration of 0.01ppm (LMR), we had an optical density of 0.928 which was in line with the standard.

- Between $270 \mathrm{~nm}$ and $280 \mathrm{~nm}$ with a concentration of $0.1 \mathrm{ppm}$ (10 times LMR) the optical density was high and gave the optical densities of 3.99 and 4.37 respectively. This could be explained by the high Propanil content of the standard.

Thus the concentration of the standard is proportional to the optical density.

We noticed that at the wavelength of $270 \mathrm{~nm}$ and 275 with a concentration of $0.1 \mathrm{ppm}$, the optical density was in the norm (0.4-0.9) while at the wavelength from $280 \mathrm{~nm}$ at the same concentration of $0.1 \mathrm{ppm}$, the optical density was higher than the standard, that it 1.206.

At the wavelength of $270 \mathrm{~nm}$ with a concentration of $0.01 \mathrm{ppm}$ (LMR), we had obtained an optical density in accordance with the standard. 
Vol. 07, No. 01; 2022

ISSN: $2456-8643$

\section{CONCLUSION}

At the end of the study, which consisted of experimenting with the analytical method for detecting Propanil residues in local rice, we had satisfactory results. Because Propanil has been identified and measured in rice using FTIR and UV Visible spectrophotometry.

Upon identification, the sample graph and the standard graph overlapped, confirming the presence of Propanil in the rice sample.

During the analysis of the assay with UV-Visible spectrophotometry, we noticed that at the concentration of the MRL, the optical density of the sample was normal and this allowed us to quantify the content of the sample in Propanil.

This method could be repeated with other pesticides used in rice cultivation, to allow the search for pesticide residues in rice, which is the staple food in Mali.

Thus, the quality control of rice by UV-Visible spectrophotometry and FTIR could be established at LNS like other consumer food products.

\section{REFERENCE}

[1] - Ednei G. Prime I, et al, Risk assessment of surface water contamination by herbicide residues: monitoring of Propanil degradation in irrigated rice field waters using HPLC-UV and confirmation by GC-MS, J. Braz. Chem. Soc. vol.18 no.3 São Paulo 2007.

[2] - Tomlin, C.D.S.; the e-Pesticide Manual, Thirteenth Edition, Version 3.0, London, 2003. 3, 4.Propanil (Ref: FW 734), DCPA 3,4-DCPA ** propanamide **

[3] - Ministry of Agriculture, May 2009. National rice development strategy

[4] - AGRO, Agence Ecofin, https://www.agenceecofin.com/riz/0903-55095-le-mali-mise-surune-production-rizicole-de-3-14-millions-de -tons-in-2018/2019

[5] - Damalas, C. A.; Eleftherohorinos, I. G. Pesticide Exposure, Safety Issues, and Risk Assessment Indicators. International Journal of Environmental Research and Public Health. 2011.

[6] - Quechers.cvua-stuttgart. Fast easy multiresidue method employing acetonitrile extraction / partitioning, dispersive solid-phase extraction for the determination of pesticide residues in produce. Accessed April 6, 2020.

[7] - EU Pesticides data base - European Commission. Retrieved July 10, 2020, from URL: https://ec.europa.eu/food/plant/pesticides/eu-pesticides-

database/public/?event=pesticide.residue.displayMRL\&language $=\mathrm{EN}$

[8] - UV-visible spectrophotometry. Principle of operation. Accessed on March 03, 2020 at the URL: $\quad$ https://www.superprof.fr/ressources/scolaire/physique-chimie/terminale-s/laspectroscopie/spectrometrie-ultraviolet-visible.html

[9] - Laurent S., 2011. Understanding infrared spectroscopy: principles and implementation. 